\title{
INFLUÊNCIA DO ESPAÇAMENTO ENTRELINHAS E DA POPULAÇÃO DE PLANTAS A UMA CULTIVAR DE SOJA DE HÁBITO DE CRESCIMENTO INDETERMINADO
}

\author{
SILVA, Alessandro Guerra da ${ }^{1}$ \\ MARTINS, Paula Daiane de Sena ${ }^{2}$ \\ CARMO, Eduardo Lima do ${ }^{3}$ \\ PROCÓPIO, Sérgio de Oliveira ${ }^{4}$ \\ ANDRADE, Christiano Lima Lobo de ${ }^{5}$ \\ CALDAS, Joao Victor Santos 6 \\ FERREIRA JÚNIOR, José Carlos ${ }^{7}$
}

\begin{tabular}{lll}
\hline Recebido em: 2020.10 .29 & Aprovado em: $2021.01 .13 \quad$ ISSUE DOI: $10.3738 / 1982.2278 .3857$
\end{tabular}

RESUMO: Os arranjos na cultura da soja podem promover alterações no desenvolvimento das plantas e, consequentemente, na produtividade de grãos. Neste contexto, o arranjo espacial aliado ao hábito de crescimento da cultivar podem ser alternativas para o manejo da cultura da soja para obtenção de maiores produtividades. Dessa forma, o objetivo deste trabalho foi avaliar o desempenho agronômico de um cultivar de hábito de crescimento indeterminado submetido a diferentes espaçamentos entrelinhas e população de plantas em condições de cerrado. $\mathrm{O}$ ensaio foi instalado em delineamento de blocos casualizados, em arranjo fatorial $4 \times 4$, com quatro repetições, correspondendo a quatro espaçamentos entrelinhas $(20 ; 40 ; 20 / 40$ e 20/60 cm) associados a quatro populações de plantas (266.667; 400.000; 533.333; e 666.667 plantas ha $^{-1}$ ) do cultivar BMX Potência RR $^{\circledR}$. Os resultados obtidos permitiram constar que os espaçamentos entrelinhas não influenciaram a produtividade bem como de seus componentes. O acréscimo de $66 \%$ na população de plantas proporcionou maiores produtividades e massa de mil grãos, massa seca da parte aérea, altura de plantas e de inserção da primeira vagem e redução apenas para o número de vagens na haste principal.

Palavras-chave: Arranjo de plantas. Componentes da produtividade. Glycine max. Produtividade de grãos.

\section{BETWEEN SPACING AND PLANT POPULATION IN CULTIVARING SOYBEAN OF INDETERMINATED GROWTH HABIT}

SUMMARY: Arrangements in soybean culture can promote changes in plant development and, consequently, in grain productivity. In this context, the spatial arrangement combined with the cultivar's growth habit can be an alternative for the management of soybean culture to obtain greater productivity. Thus, the objective of this work was to evaluate the agronomic performance of a cultivar of indeterminate growth habit submitted to different spacing between lines and plant population in cerrado conditions. The assay was installed in a randomized block design, in a $4 \times 4$ factorial arrangement, with four replications, corresponding to four leading spacing $(20 ; 40 ; 20 / 40$ and 20/60 $\mathrm{cm})$ associated with four plant populations $\left(266.667 ; 400.000 ; 533.333\right.$; and 666.667 plants $\left.^{-1}{ }^{-1}\right)$ of the cultivar BMX Poder $\mathrm{RR}^{\circledR}$. The results obtained showed that the spacing between the lines did not influence productivity as well as its components. The increase of $66 \%$ in the plant population provided greater productivity and a thousand grain

\footnotetext{
${ }^{1}$ Programa de Pós Graduação Universidade de Rio Verde. silvaag@ yahoo.com.br

${ }^{2}$ Programa de Pós Graduação Universidade de Rio Verde pauladaiane.eng@gmail.com

${ }^{3}$ Programa de Pós Graduação Professor Universidade de Rio Verde . eduardo@unirv.edu.br

${ }^{4}$ Pesquisador Embrapa tabuleiros Costeiros. procopio.so@gmail.com

${ }^{5}$ Professor UniBRAS - Faculdade Rio Verde. prof.christianolobo@gmail.com

${ }^{6}$ Graduando Universidade de Rio Verde . vscaldas@ hotmail.com

${ }^{7}$ Graduando Universidade de Rio Verde. agroferreirajr@gmail.com
} 
mass, dry mass of the aerial part, height of plants and insertion of the first pod and reduction only for the number of pods in the main stem.

Keywords: Plant arrangement. Yield components. Glycine max. Grain yield.

\section{INTRODUÇÃO}

Nos últimos anos, em função do grande desenvolvimento tecnológico ocorrido na cultura da soja, tem-se verificado um aumento exponencial no lançamento de novas cultivares de soja no mercado brasileiro. (SEDIYAMA, 2009; LUDWIG et al., 2011; PERINI et al., 2012). Este aumento no número de cultivares disponíveis torna-se uma importante ferramenta para o produtor rural tanto na redução de custos quanto no aumento da variabilidade genética disponível no campo.

No entanto, para a escolha adequada do material é necessário levar em consideração outros parâmetros assim como as condições edafoclimáticas do local de cultivo, o hábito de crescimento além do arranjo de plantas. Neste contexto, as cultivares de hábito de crescimento indeterminado aliado ao arranjo de plantas podem resultar em incrementos na produtividade de grãos de soja (MADALOSSO et al., 2010; IBRAHIM 2012; BALBINOT JUNIOR et al., 2015; SOUZA et al. 2016).

$\mathrm{O}$ arranjo de plantas resulta da combinação da população de plantas e do espaçamento das entrelinhas (PROCÓPIO et al., 2014; BALBINOT JUNIOR et al., 2018). Adicionalmente podese variar o sentido das linhas de semeadura permitindo obter melhores respostas de produtividade de grãos em função das características morfológicas do cultivar (FERREIRA et al., 2018; BALBINOT JUNIOR et al., 2018). Para o melhor desenvolvimento das cultivares de soja e obtenção de maiores valores de produtividades de grãos é imprescindível à harmonia entre os fatores ambientais, como água, luz e nutrientes (GODOI et al., 2005; GUIMARÃES et al., 2008; LIMA et al., 2008; KOMATSU et al., 2010; LUDWIG et al., 2011). Sendo assim, o arranjo de plantas melhora a distribuição das plantas na área, diminuindo a competição intraespecífica destas por esses recursos ambientais (MAUAD et al., 2010; LUDWIG et al., 2011).

Recentemente, novos arranjos de plantas, como a adoção de espaçamentos reduzidos, fileiras duplas e semeadura cruzada, vêm sendo testados com a cultura da soja no Brasil com intuito de aumentar a produtividade de grãos (BIANCHI et al., 2010; IBRAHIM, 2012; PROCÓPIO et al., 2014; BALBINOT JÚNIOR et al., 2015). Com o aumento de uso de novas

Nucleus, v.18, n.1, abr. 2021 
cultivares de soja de hábito de crescimento indeterminado, há a necessidade de se avaliar diferentes arranjos, principalmente em condições de cerrado (FERREIRA et al., 2019).

Neste cenário, torna-se oportuno avaliar as possíveis alterações que o arranjo de plantas ocasionar no desenvolvimento de plantas de soja de hábito de crescimento indeterminado (FERREIRA et al., 2019), bem como seus efeitos nos componentes e na produtividade de grãos. Mediante ao exposto, o objetivo deste trabalho foi avaliar os efeitos do espaçamento entrelinhas e população de plantas na produtividade e de seus componentes de uma cultivar de soja de hábito de crescimento indeterminado cultivada em condições de cerrado.

\section{MATERIAL E MÉTODO}

O ensaio foi conduzido a campo, no município de Rio Verde-GO, na região Sudoeste de Goiás (1748’09,46”S; 5059’58,65”'W e altitude de $750 \mathrm{~m}$ ) na safra agrícola 2012/13, em solo classificado como Latossolo Vermelho distroférrico (EMBRAPA, 2006), cultivado no sistema plantio direto. Os dados de precipitação e temperatura média do ar durante a condução do experimento estão apresentados na Figura 1.

Figura 1. Valores de precipitação e temperatura média do ar durante a condução do ensaio. Rio Verde-GO, safra 2012/13.

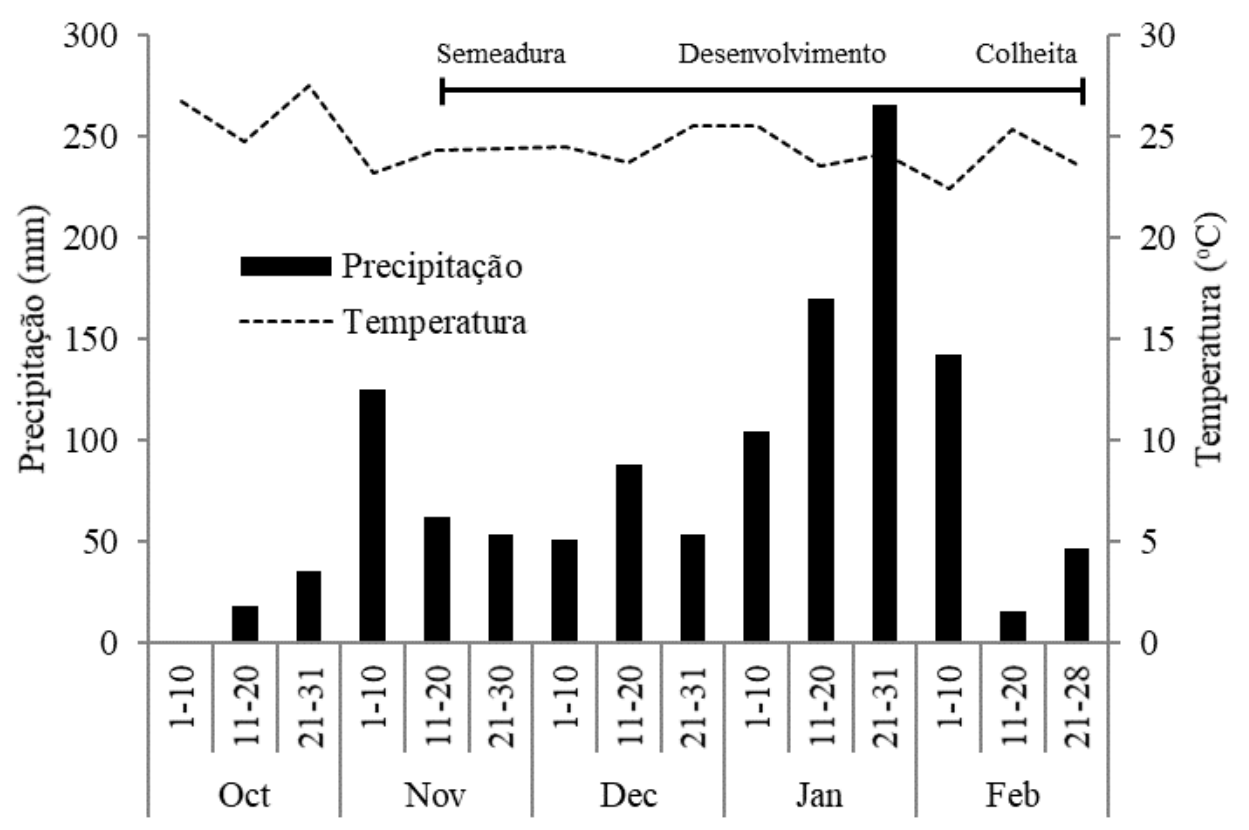

Fonte: Elaborado pelos Autores 
A coleta das amostras simples, para formação da amostra composta de solo, foi realizada na profundidade de 0 a $20 \mathrm{~cm}$ contém as seguintes características: $\mathrm{pH}$ em $\mathrm{CaCl}_{2}$ : 4,4; Ca: 1,6; Mg: 0,8; K: 0,2; Al: 0,5; H+Al: 4,8; CTC: 7,4 e SB: 2,6, em $\mathrm{cmol}_{\mathrm{c}} \mathrm{dm}^{-3} ; \mathrm{P}: 1,8 \mathrm{mg} \mathrm{dm}^{-3}$; saturação de bases e de alumínio: 35 e 16\% respectivamente; argila, silte e areia: 500, 110 e 390 $\mathrm{g} \mathrm{kg}^{-1}$, respectivamente. A cultivar utilizada foi a BMX Potência $\mathrm{RR}^{\circledR}$, caracterizada por possuir hábito de crescimento indeterminado com grupo de maturação 6.7 para a região de cultivo, apresenta porte alto, cor da flor branca, pubescência cinza e hilo marrom claro.

O delineamento experimental empregado foi de blocos casualizados com quatro repetições. Foi utilizado o arranjo fatorial, 4x4, sendo que os tratamentos corresponderam à combinação dos quatro espaçamentos entrelinhas $(0,2 \mathrm{~m}$ : reduzido; $0,4 \mathrm{~m}$ : convencional; 0,2/0,4 $\mathrm{m}$ : fileiras duplas reduzidas; e 0,2/0,6 m: fileiras duplas) associados a quatro populações de plantas ha ${ }^{-1}\left(266.667 ; 400.000 ; 533.333\right.$ e 666.667 plantas $\left.\mathrm{ha}^{-1}\right)$ correspondendo a $66 \%$ da população recomendada, população recomendada e acréscimos de 33 e 66\%, respectivamente.

As parcelas apresentaram 5,0 m de comprimento por 3,2 $\mathrm{m}$ de largura. A área útil foi obtida desconsiderando-se 0,4 $\mathrm{m}$ de cada lado e 1,0 $\mathrm{m}$ de cada extremidade para todos os tratamentos, apresentando, portanto $7,2 \mathrm{~m}^{2}$. Assim, foram consideradas como linhas úteis das parcelas, seis linhas para os espaçamentos de 0,4 e de $0,2 / 0,6 \mathrm{~m}$, oito para o de $0,2 / 0,4 \mathrm{~m}$ e doze linhas para o espaçamento entrelinhas de $0,2 \mathrm{~m}$.

Uma semana antes da semeadura, as plantas daninhas foram dessecadas com uso de 1.920 g e.a. $\mathrm{ha}^{-1}$ de glyphosate e 536 g i.a. ha ${ }^{-1}$ de 2,4-D aplicados em volume de calda equivalente a $150 \mathrm{~L} \mathrm{ha}^{-1}$. Posteriormente, foi realizada adubação a lanço, de forma mecanizada, na proporção de $400 \mathrm{~kg} \mathrm{ha}^{-1}$ da fórmula 08-20-18. No dia da semeadura, as sementes foram tratadas com

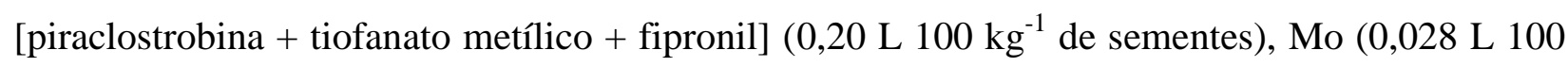
$\mathrm{kg}^{-1}$ de sementes) e com o inoculante líquido (Bradyrhizobium elkanii; concentração de $5 \times 10^{9}$ ) na

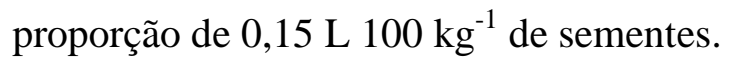

A semeadura foi realizada mecanicamente em 23 de novembro de 2012, com uso de semeadora de parcelas, composta de dezesseis linhas espaçadas de $0,2 \mathrm{~m}$, na profundidade de 5 cm. O desbaste foi realizado dez dias após a emergência das plântulas (DAE), sendo retiradas as linhas e o número de plantas excedentes para composição dos respectivos tratamentos. No mesmo dia foi realizada adubação em cobertura de forma manual, a lanço, com aplicação de 200 $\mathrm{kg} \mathrm{ha}^{-1}$ de $\mathrm{KCl}$.

Nucleus, v.18, n.1, abr. 2021 
O controle das plantas daninhas foi realizado aos 12 DAE com aplicação de 1.440 g e.a. $\mathrm{ha}^{-1}$ de glyphosate. Para o controle de lagartas desfolhadoras, foi aplicado $0,15 \mathrm{~L} \mathrm{ha}^{-1} \mathrm{de}$ bifentrina $+0,20 \mathrm{~L} \mathrm{ha}^{-1}$ de teflubenzurom aos 12 e 20 DAE. O controle de mosca branca (Bemisia tabaci) fez-se necessário aos $26 \mathrm{DAE}$, com aplicação de $1,0 \mathrm{~L} \mathrm{ha}^{-1}$ de [imidacloprido + betaciflutrina]. A aplicação de fungicida foi realizada quando as plantas de soja estavam com 34 DAE, com 0,6 L ha ${ }^{-1}$ do fungicida [piraclostrobina + epixiconazole], juntamente com $0,04 \mathrm{~L} \mathrm{ha}^{-1}$ do inseticida clorantraniliprole. Outra aplicação de inseticida foi realizada aos 46 DAE na proporção de 0,3 $\mathrm{L} \mathrm{ha}^{-1}$ Bacillus thuringiensis $+0,25 \mathrm{~L} \mathrm{ha}^{-1}$ de [thiamethoxam + cipermetrina]. Por fim, foi realizada aplicação de inseticida e fungicida aos 58 DAE com $0,09 \mathrm{~L} \mathrm{ha}^{-1}$ de methoxyfenozide $+0,5 \mathrm{~kg} \mathrm{ha}^{-1}$ de acefato $+0,3 \mathrm{~L} \mathrm{ha}^{-1}$ de [azoxistrobina + ciproconazol]. Todos os tratos culturais fitossanitários foram feitos com auxílio de pulverizador tratorizado com emprego de volume de calda equivalente a $200 \mathrm{~L} \mathrm{ha}^{-1}$.

A colheita foi realizada aos 118 DAE, 7 dias após a BMX Potência RR $^{\circledR}$ ter atingido a maturidade fisiológica. Posteriormente foi avaliada, na área útil das parcelas, a produtividade de grãos (pesagem dos grãos com correção da umidade para 13\%, com posterior conversão para kg ha $^{-1}$ ); massa de mil grãos (contagem e pesagem de mil grãos a partir de amostra retirada da massa de grãos colhidos por parcela); massa seca da parte aérea (colheita aleatória de dez plantas no estádio de completo enchimento de grãos- $\mathbf{R}_{6}$, com posterior secagem em estufa de circulação forçada de ar a $65^{\circ} \mathrm{C}$ por $72 \mathrm{~h}$. Em seguida efetuou-se a pesagem das amostras).

Adicionalmente foram avaliadas a altura de plantas (medição do colo até a extremidade da haste principal de dez plantas escolhidas aleatoriamente nas parcelas); e de inserção da primeira vagem (medição do colo até a inserção da primeira vagem em dez plantas escolhidas aleatoriamente nas parcelas); número de vagens por planta na haste principal e nas ramificações primárias (separação das vagens contendo três, dois e um grão); e número de ramificações primárias por planta (contagem do número de ramificações) sendo avaliadas dez plantas escolhidas aleatoriamente.

Os dados foram submetidos à análise de variância. Quando constatada significância para determinada variável, empregou-se o teste de Tukey a 5\% de probabilidade, e análise de regressão para comparação das médias referentes aos espaçamentos entrelinhas e populações de plantas, respectivamente. Previamente a realização da ANOVA foram realizados os testes de normalidade e homogeneidade para verificar as pressuposições estatísticas, e quando necessário 
os dados foram transformados para raiz quadrada de $(\mathrm{x}+1)$. Foi empregado o software estatístico Sisvar ${ }^{\circledR}$ desenvolvido pela Universidade Federal de Lavras.

\section{RESULTADO E DISCUSSÃO}

Os resultados obtidos permitiram constatar o efeito da população de plantas em todas as características avaliadas, fato não observado para o espaçamento entrelinhas (Tabela 1). Além disto, não foi observada interação entre o espaçamento e a população de plantas para nenhuma das características avaliadas.

Tabela 1. Resultados análise de variância para as variáveis: produtividade de grãos (PROD), massa de mil grãos (MMG), massa seca da parte aérea (MS), altura de planta (AP) e de inserção da primeira vagem (AIV), número de vagens na haste principal (NVHP) com três (NVHP3G), dois (NVHP2G) e um grão (NVHP1G), número de ramificações primárias (NRP) e de vagens na ramificação primária (NVRP) com três (NVRP3G), dois (NVRP2G) e um grão (NVRP1G) do ensaio de arranjos de plantas da cultivar BMX Potência RR ${ }^{\circledR}$, Rio Verde - GO, safra 2012/13.

\begin{tabular}{|c|c|c|c|c|c|c|}
\hline Fonte de Variação & GL & PROD & MMG & MS & AP & AIV \\
\hline Espaçamento (E) & 3 & ns & ns & ns & $\mathrm{ns}$ & ns \\
\hline População (P) & 3 & $* *$ & $* *$ & $* *$ & $* *$ & $* *$ \\
\hline Ex P & 9 & ns & ns & ns & ns & ns \\
\hline Coefic. variação (\%) & & 15,7 & 4,9 & 29,4 & 7,4 & 13,7 \\
\hline Fonte de Variação & GL & NVHP & NVHP3G & NVHP2G & & NVHP1G \\
\hline Espaçamento (E) & 3 & ns & ns & Ns & & ns \\
\hline População (P) & 3 & $* *$ & $* *$ & $* *$ & & $* *$ \\
\hline $\mathrm{E} \times \mathrm{P}$ & 9 & ns & ns & Ns & & ns \\
\hline Coefic. variação (\%) (\%) & & 16,8 & 17,0 & 20,4 & & 50,1 \\
\hline Fonte de Variação & GL & NRP & NVRP & NVRP3G & NVRP2G & NVRP1G \\
\hline Espaçamento (E) & 3 & ns & ns & ns & ns & ns \\
\hline População (P) & 3 & $* *$ & $* *$ & $* *$ & $* *$ & $* *$ \\
\hline $\mathrm{E} \times \mathrm{P}$ & 9 & ns & ns & ns & ns & ns \\
\hline Coefic. variação (\%) & & 23,8 & 43,4 & 62,7 & 41,2 & 49,2 \\
\hline
\end{tabular}

$* *, *,{ }^{\text {ns }}$ : significativo a 1 e $5 \%$ de probabilidade e não significativo, respectivamente, pelo teste $\mathrm{F}$. GL: Graus de liberdade.

Fonte: Elaborado pelos Autores

$\mathrm{Na}$ medida em que se aumentou a população de plantas foi possível ter incrementos na produtividade de grãos da BMX Potência $\mathrm{RR}^{\circledR}$ (Figura 2). Este resultado permite destacar a importância do aumento do número de plantas na área quando se objetiva aumentos de produtividade em semeaduras tardias da soja, mesmo que possa constatar diminuição de outros componentes de produtividade. Nessa condição constata-se a indução mais precoce do florescimento das plantas de soja, principalmente em regiões de menores latitudes, o que 
ocasiona redução da altura de plantas (FERREIRA et al., 2010; FERREIRA et al., 2019). Com isto tem-se menor espaço ocupado pelas plantas, permitindo assim o aumento da população.

Figura 2. Produtividade de grãos (PROD) do cultivar BMX Potência $R^{\circledR}{ }^{\circledR}$ em função do aumento na população de plantas, Rio Verde - GO, safra 2012/13.

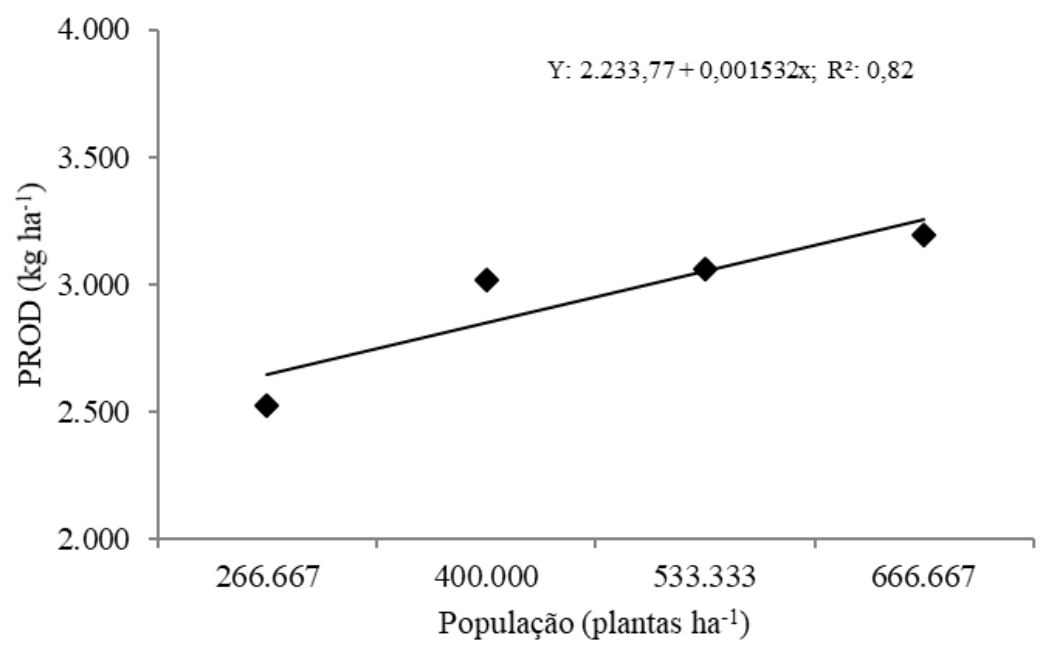

Fonte: Elaborado pelos Autores

Adicionalmente, na medida em que houve o aumento da população de plantas ocorreram incrementos na massa de mil grãos (Figura 3). Com maior população há o estímulo do crescimento apical ao invés da ramificação lateral em função da competição por luz. Com menor número de ramos laterais ocorrerá também redução número de vagens por planta e da massa de mil grãos em função da competição interespecífica pelo maior número de plantas na área (FERREIRA et al., 2018; FERREIRA et al., 2019), fato que não ocorreu neste experimento.

Isto pode ser atribuído ao comportamento morfológico da BMX Potência RR. Cultivares de crescimento indeterminado possuem folíolos pequenos e ligeiramente verticais, o que lhes confere pouca capacidade de ramificação, favorecendo a captação de luz (PROCÓPIO et al., 2014). Além disso, após a floração o crescimento continua concomitante aos estádios reprodutivos, estimulando as atividades metabólicas e fotossintéticas podendo potencializar a síntese de metabolitos e o transporte para os grãos (PROCÓPIO et al., 2014; BALBINOT JUNIOR et al., 2018). 
Figura 3. Valores médios de massa de mil grãos (MMG) do cultivar BMX Potência RR $^{\circledR}$ em função do aumento na população de plantas, Rio Verde - GO, safra 2012/13.

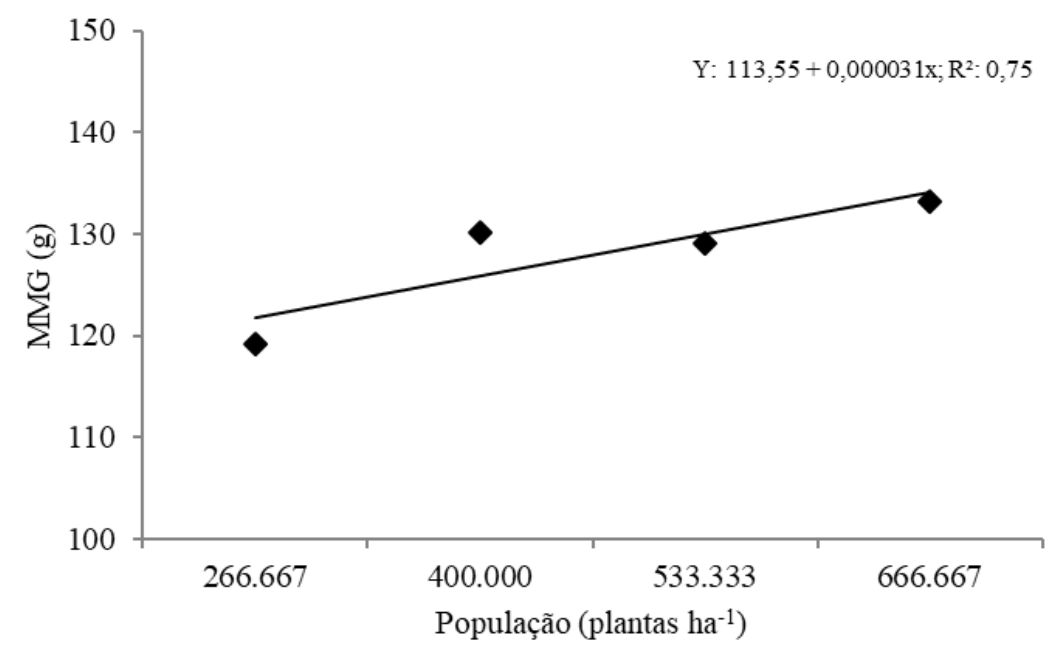

Fonte: Elaborado pelos Autores

No experimento, os espaçamentos entrelinhas não influenciaram a produtividade e a massa de mil grãos da BMX Potência $\mathrm{RR}^{\circledR}$ (Tabela 2). Associada a época de semeadura mais tardia, como relatado anteriormente, cultivares de hábito de crescimento indeterminado, em função do tamanho e disposição dos folíolos, são menos susceptíveis a interferência do arranjo das plantas, vistos que morfologicamente encontram-se adaptados à captação de luz (MADALOSSO et al., 2010). No entanto, a capacidade da planta de se adaptar aos diferentes espaçamentos alterar sua morfologia e possam ter contribuído para a ausência de diferenças para essas variáveis.

Semelhante ao observado para as demais características, o aumento da população de plantas proporcionou acréscimo da massa seca da parte aérea (Figura 4), semelhante ao observado por Procópio et al. (2014) no cultivar de soja BRS 294 RR $^{\circledR}$ de hábito de crescimento indeterminado. Os autores atribuem o aumento dessa variável ao fato de serem cultivares com plantas mais compactas e com ramificação próxima à haste, o que permite maior acúmulo de massa seca da parte aérea por unidade de área com o aumento populacional.

Esperava-se que reduções no espaçamento entrelinhas pudessem acarretar modificações no fechamento das entrelinhas e no índice de área foliar, favorecendo o acúmulo da matéria seca (PROCÓPIO et al., 2014). No entanto a responsividade da soja a alterações do espaçamento está 
relacionada às condições do ambiente e ao cultivar empregado (FERREIRA et al., 2019). Neste caso o uso de uma cultivar de hábito de crescimento indeterminado, cuja arquitetura favorece a expressão da plasticidade fenotípica, a época de semeadura tardia e o baixo volume de chuvas acumulado no primeiro decêndio após a implantação da cultura possa ter contribuído para ausência de efeitos dos espaçamentos entrelinhas para as variáveis analisadas.

Tabela 2. Valores médios da produtividade de grãos (PROD), massa de mil grãos (MMG), massa seca da parte aérea (MS), altura de planta (AP) e de inserção da primeira vagem (AIV) do cultivar BMX Potência RR em função da combinação de espaçamentos entrelinhas e população de plantas, Rio Verde - GO, safra 2012/13.

\begin{tabular}{|c|c|c|c|c|c|}
\hline \multirow{2}{*}{$\begin{array}{l}\text { Espaçamento } \\
\text { entrelinhas }(\mathrm{cm})\end{array}$} & \multicolumn{4}{|c|}{ População (plantas ha"-1) } & \multirow{2}{*}{ Médias } \\
\hline & 266.667 & 400.000 & 533.333 & 666.667 & \\
\hline & \multicolumn{4}{|c|}{ PROD $\left(\mathrm{kg} \mathrm{ha}^{-1}\right)$} & \\
\hline 20 & $2.433 \mathrm{a}$ & $3.198 \mathrm{a}$ & $3.364 \mathrm{a}$ & $3.135 \mathrm{a}$ & $3.033 \mathrm{a}$ \\
\hline 40 & $2.684 \mathrm{a}$ & $2.991 \mathrm{a}$ & $2.924 \mathrm{a}$ & $3.104 \mathrm{a}$ & $2.926 \mathrm{a}$ \\
\hline $20 / 40$ & $2.610 \mathrm{a}$ & $2.974 \mathrm{a}$ & $3.028 \mathrm{a}$ & $3.503 \mathrm{a}$ & $3.029 \mathrm{a}$ \\
\hline $20 / 60$ & $2.375 \mathrm{a}$ & $2.911 \mathrm{a}$ & $2.910 \mathrm{a}$ & $3.032 \mathrm{a}$ & $2.807 \mathrm{a}$ \\
\hline \multirow[t]{2}{*}{ Médias } & 2.525 & 3.019 & 3.057 & 3.194 & 2.949 \\
\hline & \multicolumn{4}{|c|}{ MMG (g) } & \\
\hline 20 & $116,0 \mathrm{a}$ & $128,7 \mathrm{a}$ & 127,6 a & $131,5 \mathrm{a}$ & $126,0 \mathrm{a}$ \\
\hline 40 & $123,1 \mathrm{a}$ & $131,3 \mathrm{a}$ & $128,7 \mathrm{a}$ & $130,0 \mathrm{a}$ & $128,3 \mathrm{a}$ \\
\hline $20 / 40$ & $117,5 \mathrm{a}$ & $131,3 \mathrm{a}$ & $127,3 \mathrm{a}$ & $135,0 \mathrm{a}$ & $127,8 \mathrm{a}$ \\
\hline $20 / 60$ & $119,7 \mathrm{a}$ & $129,7 \mathrm{a}$ & $132,6 \mathrm{a}$ & $136,1 \mathrm{a}$ & $129,5 \mathrm{a}$ \\
\hline \multirow[t]{2}{*}{ Médias } & 119,1 & 130,2 & 129,0 & 133,2 & 127,9 \\
\hline & \multicolumn{4}{|c|}{ MS $\left(\mathrm{kg} \mathrm{ha}^{-1}\right)$} & \\
\hline 20 & $6.286 \mathrm{a}$ & $6.052 \mathrm{a}$ & $6.962 \mathrm{a}$ & $8.758 \mathrm{a}$ & $7.014 \mathrm{a}$ \\
\hline 40 & $5.549 \mathrm{a}$ & $6.152 \mathrm{a}$ & $6.040 \mathrm{a}$ & $6.807 \mathrm{a}$ & $6.137 \mathrm{a}$ \\
\hline $20 / 40$ & $5.886 \mathrm{a}$ & $6.917 \mathrm{a}$ & $7.263 \mathrm{a}$ & $10.238 \mathrm{a}$ & $7.576 \mathrm{a}$ \\
\hline $20 / 60$ & $5.464 \mathrm{a}$ & $8.311 \mathrm{a}$ & $6.479 \mathrm{a}$ & $7.036 \mathrm{a}$ & $6.823 \mathrm{a}$ \\
\hline \multirow[t]{2}{*}{ Médias } & 5.796 & 6.858 & 6.686 & 8.210 & 6.888 \\
\hline & \multicolumn{4}{|c|}{$\mathrm{AP}(\mathrm{cm})$} & \\
\hline 20 & $64,2 \mathrm{a}$ & $70,8 \mathrm{a}$ & $72,0 \mathrm{a}$ & $75,1 \mathrm{a}$ & $70,5 \mathrm{a}$ \\
\hline 40 & 64,3 a & $68,0 \mathrm{a}$ & $64,5 \mathrm{a}$ & $72,5 \mathrm{a}$ & 67,3 a \\
\hline $20 / 40$ & $61,8 \mathrm{a}$ & $71,6 \mathrm{a}$ & $72,8 \mathrm{a}$ & $70,7 \mathrm{a}$ & $69,2 \mathrm{a}$ \\
\hline $20 / 60$ & $63,0 \mathrm{a}$ & $73,7 \mathrm{a}$ & 68,8 a & 72,7 a & $69,6 \mathrm{a}$ \\
\hline \multirow[t]{2}{*}{ Médias } & 63,3 & 71,0 & 69,5 & 72,7 & 69,1 \\
\hline & \multicolumn{4}{|c|}{ AIV $(\mathrm{cm})$} & \\
\hline 20 & 16,8 a & $17,7 \mathrm{a}$ & $19,2 \mathrm{a}$ & $18,8 \mathrm{a}$ & $18,1 \mathrm{a}$ \\
\hline 40 & $17,2 \mathrm{a}$ & $16,4 \mathrm{a}$ & $20,2 \mathrm{a}$ & $16,3 \mathrm{a}$ & $17,5 \mathrm{a}$ \\
\hline $20 / 40$ & $14,2 \mathrm{a}$ & $15,4 \mathrm{a}$ & $18,2 \mathrm{a}$ & $19,2 \mathrm{a}$ & $16,8 \mathrm{a}$ \\
\hline $20 / 60$ & $15,4 \mathrm{a}$ & $15,0 \mathrm{a}$ & $17,2 \mathrm{a}$ & $18,9 \mathrm{a}$ & $16,6 \mathrm{a}$ \\
\hline Médias & 15,9 & 16,1 & 18,7 & 18,3 & 17,2 \\
\hline
\end{tabular}

* Médias seguidas pela mesma letra na coluna não diferem entre si pelo teste de Tukey a 5\% de probabilidade. 
Figura 4. Valores médios de massa seca da parte aérea (MS) de plantas do cultivar BMX Potência $\mathrm{RR}^{\circledR}$ em função do aumento na população de plantas, Rio Verde - GO, safra 2012/13.

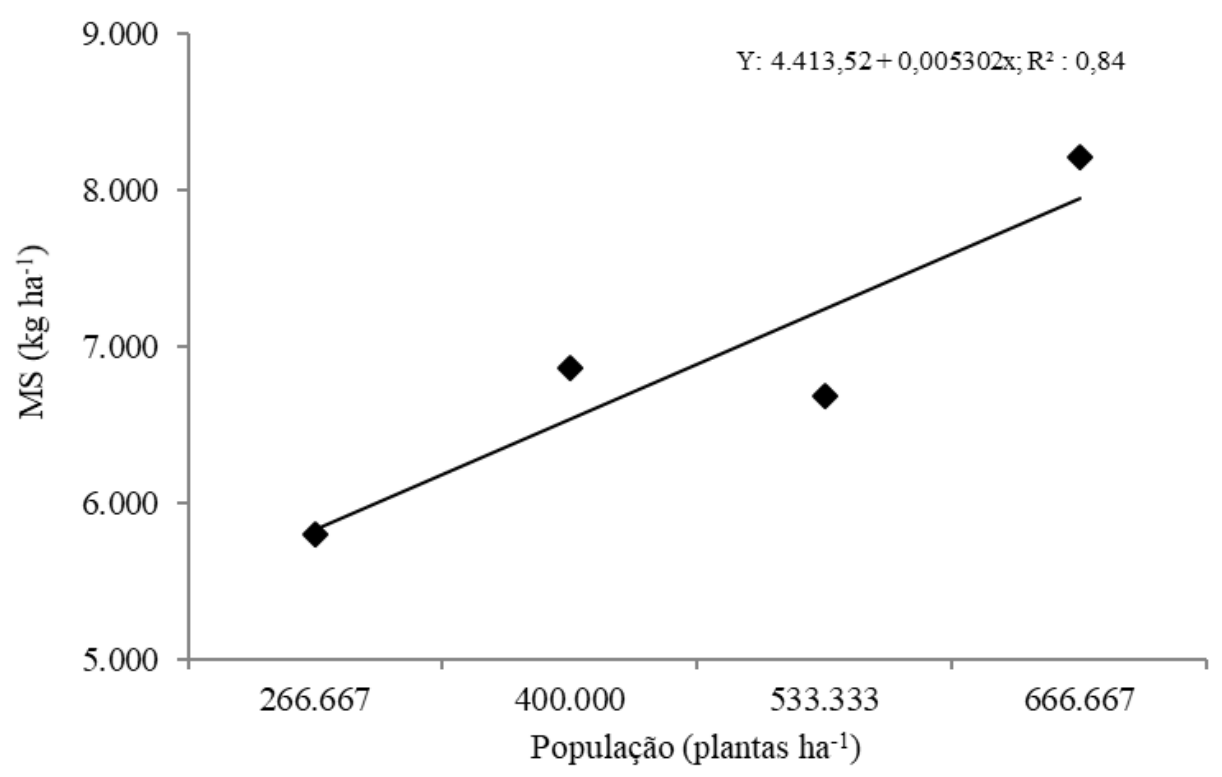

Fonte: Elaborado pelos Autores

Semelhantemente as demais variáveis, os espaçamentos entrelinhas não influenciaram a altura das plantas e de inserção da primeira vagem (Tabela 2), assim como o observado por Procópio et al. (2013) em cultivar de mesmo hábito de crescimento. No entanto, aumentos nos valores destas duas variáveis foram constatados com o incremento da população de plantas (Figura 5), o qual é atribuído à competição intraespecífica das plantas de soja por luz. Nas maiores populações, há um redirecionamento dos metabolitos oriundos da fotossíntese para o crescimento apical, havendo menor formação de ramos laterais (MAUAD et al., 2010; PROCÓPIO et al., 2014), justificando assim o aumento dos valores das variáveis supracitadas.

É importante frisar que em todos os tratamentos, a altura de inserção da primeira vagem estava acima do recomendado para efetuar a colheita mecanizada da soja (MAUAD et al., 2010). Afinal, a inserção da primeira vagem é uma característica importante para formação dos componentes de produtividade, visto que determina a regulagem da colhedora, e, consequentemente perda de grãos.

Nucleus, v.18, n.1, abr. 2021 
Figura 5. Valores médios de altura de plantas (AP) e da inserção da primeira vagem (AIV) do cultivar BMX Potência $\mathrm{RR}^{\circledR}$ em função do aumento na população de plantas, Rio Verde - GO, safra 2012/13.

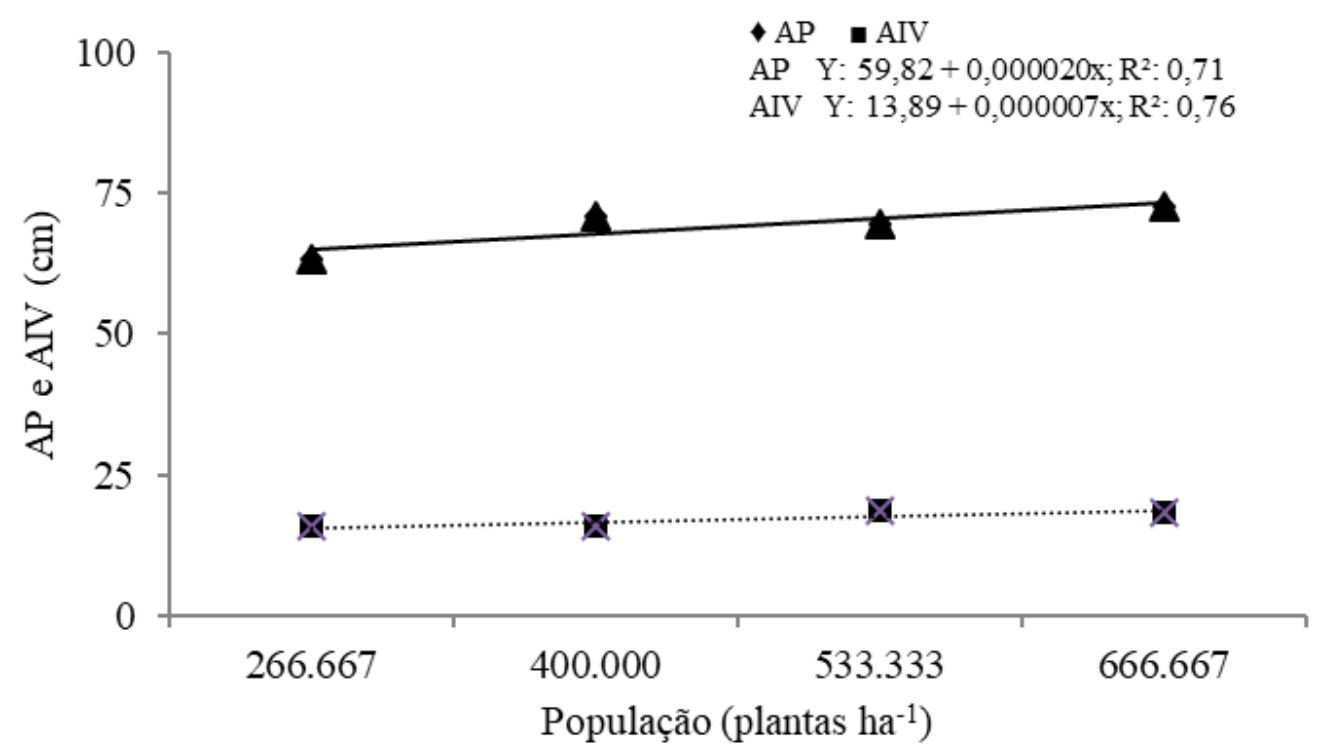

Fonte: Elaborado pelos Autores

$\mathrm{Na}$ análise dos componentes da produtividade, os espaçamentos entrelinhas não influenciaram o número de vagens na haste principal, bem como o de vagens com três, dois e um grão (Tabela 3). Com a redução do espaçamento e consequentemente com o aumento da distância das plantas na linha de semeadura, esperavam-se incrementos no número de vagens na haste principal. Embora isto não tenha ocorrido, os resultados levam a crer que cultivares de soja com características semelhantes à da BMX Potência $\mathrm{RR}^{\circledR}$ quando impostas a diferentes espaçamentos, haverá uma compensação dos componentes de produtividade, mantendo a estabilidade produtiva da cultivar (SILVA et al., 2010). 
Tabela 3. Valores médios de vagens na haste principal por planta (NVHP) com três (NVHP3G), dois (NVHP2G) e um grão (NVHP1G) do cultivar BMX Potência RR ${ }^{\circledR}$ em função da combinação de espaçamentos entrelinhas e população de plantas, Rio Verde - GO, safra 2012/13.

\begin{tabular}{cccccc}
\hline $\begin{array}{c}\text { Espaçamento } \\
\text { entrelinhas }(\mathrm{cm})\end{array}$ & 266.667 & 400.000 & 533.333 & 666.667 & Médias \\
\hline & & & NVHP & \\
20 & $22,8 \mathrm{a}$ & $19,1 \mathrm{a}$ & $15,6 \mathrm{a}$ & $14,5 \mathrm{a}$ & $18,0 \mathrm{a}$ \\
40 & $20,2 \mathrm{a}$ & $18,7 \mathrm{a}$ & $15,8 \mathrm{a}$ & $14,7 \mathrm{a}$ & $17,3 \mathrm{a}$ \\
$20 / 40$ & $21,6 \mathrm{a}$ & $19,5 \mathrm{a}$ & $17,0 \mathrm{a}$ & $13,8 \mathrm{a}$ & $18,0 \mathrm{a}$ \\
$20 / 60$ & $22,6 \mathrm{a}$ & $19,7 \mathrm{a}$ & $16,5 \mathrm{a}$ & $16,3 \mathrm{a}$ & $18,8 \mathrm{a}$ \\
Médias & 21,8 & 19,3 & 16,2 & 14,8 & 18,0 \\
\hline & & & NVHP3G & & \\
20 & $15,4 \mathrm{a}$ & $12,9 \mathrm{a}$ & $10,2 \mathrm{a}$ & $9,4 \mathrm{a}$ & $12,0 \mathrm{a}$ \\
40 & $12,7 \mathrm{a}$ & $12,3 \mathrm{a}$ & $10,7 \mathrm{a}$ & $9,0 \mathrm{a}$ & $11,2 \mathrm{a}$ \\
$20 / 40$ & $13,9 \mathrm{a}$ & $12,2 \mathrm{a}$ & $10,9 \mathrm{a}$ & $9,3 \mathrm{a}$ & $11,6 \mathrm{a}$ \\
$20 / 60$ & $15,3 \mathrm{a}$ & $12,9 \mathrm{a}$ & $10,5 \mathrm{a}$ & $10,2 \mathrm{a}$ & $12,2 \mathrm{a}$ \\
Médias & 14,3 & 12,6 & 10,6 & 9,5 & 11,7 \\
\hline & & & & \\
20 & $6,2 \mathrm{a}$ & $4,8 \mathrm{a}$ & $4,3 \mathrm{a}$ & $4,4 \mathrm{a}$ & $4,9 \mathrm{a}$ \\
40 & $5,8 \mathrm{a}$ & $5,2 \mathrm{a}$ & $4,4 \mathrm{a}$ & $4,8 \mathrm{a}$ & $5,0 \mathrm{a}$ \\
$20 / 40$ & $6,4 \mathrm{a}$ & $5,9 \mathrm{a}$ & $5,4 \mathrm{a}$ & $3,6 \mathrm{a}$ & $5,3 \mathrm{a}$ \\
$20 / 60$ & $6,3 \mathrm{a}$ & $5,7 \mathrm{a}$ & $5,3 \mathrm{a}$ & $5,1 \mathrm{a}$ & $5,6 \mathrm{a}$ \\
Médias & 6,2 & 5,4 & 4,9 & 4,5 & 5,2 \\
\hline & & & & \\
20 & $0,8 \mathrm{a}$ & $1,0 \mathrm{a}$ & $0,8 \mathrm{a}$ & $0,5 \mathrm{a}$ & $0,8 \mathrm{a}$ \\
40 & $1,6 \mathrm{a}$ & $0,9 \mathrm{a}$ & $0,5 \mathrm{a}$ & $0,7 \mathrm{a}$ & $0,9 \mathrm{a}$ \\
$20 / 40$ & $1,1 \mathrm{a}$ & $1,2 \mathrm{a}$ & $0,7 \mathrm{a}$ & $0,7 \mathrm{a}$ & $0,9 \mathrm{a}$ \\
$20 / 60$ & $0,6 \mathrm{a}$ & $1,0 \mathrm{a}$ & $0,3 \mathrm{a}$ & $0,7 \mathrm{a}$ & $0,6 \mathrm{a}$ \\
Médias & 1,0 & 1,0 & 0,6 & 0,6 & 0,8 \\
\hline
\end{tabular}

* Médias seguidas pela mesma letra na coluna não diferem entre si pelo teste de Tukey a 5\% de probabilidade.

Fonte: Elaborado pelos Autores

Por outro lado, com o aumento da população houve decréscimos no número de vagens da haste principal, bem como a ocorrência de vagens com três, dois e um grão (Figura 6). Neste aspecto ficou evidenciado que em um ambiente com maior número de plantas a competição intraespecífica implicará em menor síntese de metabolitos e distribuição irregular nas plantas, limitando a formação de vagens e o enchimento de grãos (BALBINOT JÚNIOR et al., 2015). Além disso, em altas populações a soja pode ficar mais suscetível a diminuição na ocorrência e intensidade de chuvas (Figura 1) (CARMO et al., 2018 a; CARMO et al., 2018 b;), o que pode ocasionar decréscimos no número de vagens na haste principal, assim como o ocorrido neste trabalho. 
Figura 6. Valores médios de vagens na haste principal (NVHP) com três (NVHP3G), dois (NVHP2G) e um grão (NVHP1G) do cultivar BMX Potência RR ${ }^{\circledR}$ em função do aumento na população de plantas, Rio Verde - GO, safra 2012/13.

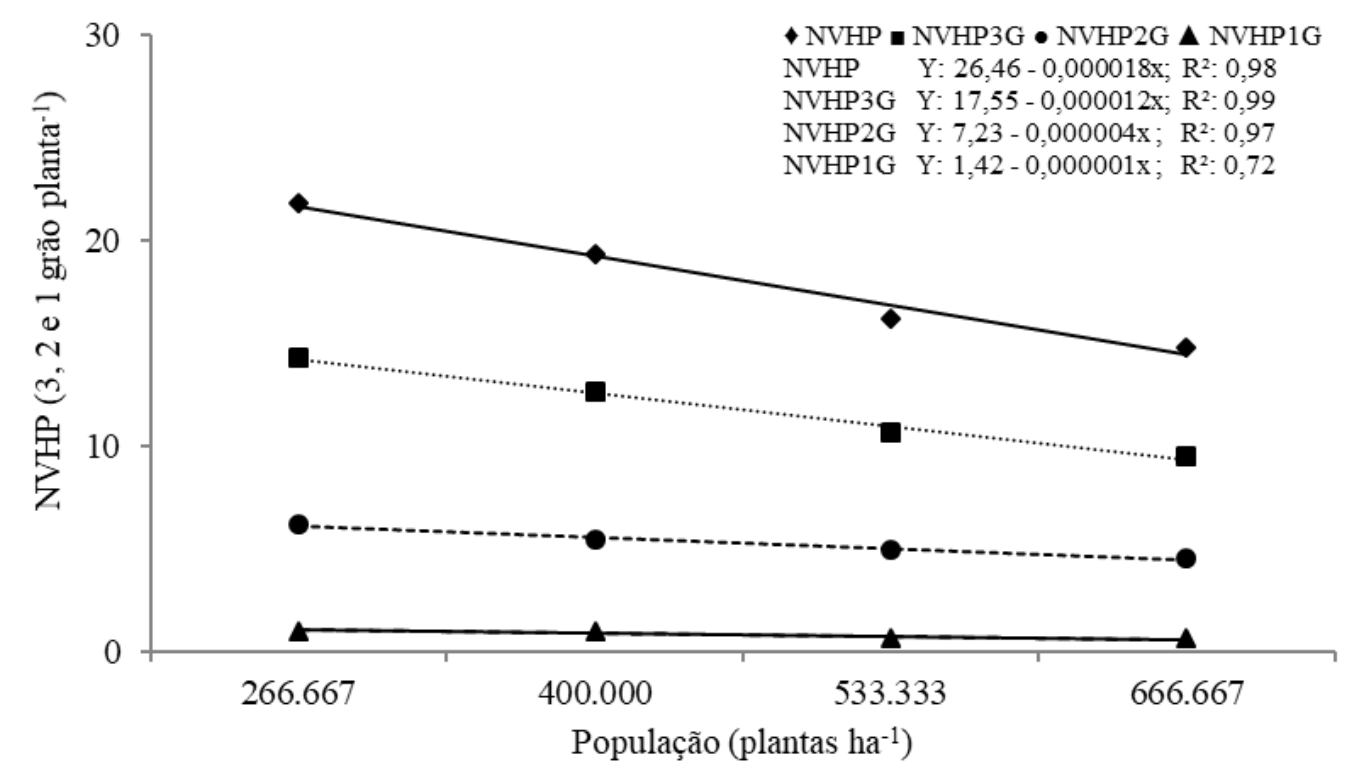

Fonte: Elaborado pelos Autores

O número de ramificações primárias e número de vagens, independentemente do número de grãos por vagem, também não foram influenciadas pelos espaçamentos entrelinhas (Tabela 4). Por outro lado, a menor população de plantas proporcionou maior número de ramificações primárias (Figura 7). Este fato é justificado pela menor competição intraespecífica das plantas em relação aos tratamentos com maior número de plantas (MAUAD et al., 2010).

Semelhantemente, a formação de vagens diminuiu com o aumento da população de plantas (Figura 8). Isto fez com que ocorresse redução no número de ramificações primárias, além do aumento da altura de plantas. Como consequência, as plantas apresentaram hastes principais mais finas, de maior suscetibilidade ao acamamento, como observado por Ferreira et al. (2018). É importante frisar que tudo isto ocasionou menor produtividade de grãos por planta. Convém ressaltar que a maior parte das vagens, e consequentemente dos grãos, foram formados na haste principal e não nas ramificações primárias, como destacado por Procópio et al. (2014). Por isto é importante avaliar este componente de produtividade, pois o aumento de vagens na haste principal, com supressão na emissão de ramificações primárias, pode ser viável quando se objetiva aumentos de produtividade. 
Tabela 4. Valores médios do número de ramificações primárias por planta (NRP), de vagens na ramificação primária (NVRP), com três (NVRP3G), dois (NVRP2G) e um grão (NVRP1G) do cultivar BMX Potência $\mathrm{RR}^{\circledR}$ em função da combinação de espaçamentos entrelinhas e população de plantas, Rio Verde - GO, safra 2012/13.

\begin{tabular}{|c|c|c|c|c|c|}
\hline \multirow{2}{*}{$\begin{array}{c}\text { Espaçamento } \\
\text { entrelinhas }(\mathrm{cm})\end{array}$} & \multicolumn{4}{|c|}{ População (plantas ha ${ }^{-1}$ ) } & \multirow{2}{*}{ Médias } \\
\hline & 266.667 & 400.000 & 533.333 & 666.667 & \\
\hline & & & NPB & & \\
\hline 20 & $3,7 \mathrm{a}$ & $1,8 \mathrm{a}$ & $1,4 \mathrm{a}$ & $1,5 \mathrm{a}$ & $2,1 \mathrm{a}$ \\
\hline 40 & $3,1 \mathrm{a}$ & $2,0 \mathrm{a}$ & $2,1 \mathrm{a}$ & $1,2 \mathrm{a}$ & $2,1 \mathrm{a}$ \\
\hline $20 / 40$ & $3,2 \mathrm{a}$ & $2,4 \mathrm{a}$ & $1,3 \mathrm{a}$ & $1,6 \mathrm{a}$ & $2,1 \mathrm{a}$ \\
\hline $20 / 60$ & $3,2 \mathrm{a}$ & $2,1 \mathrm{a}$ & $1,6 \mathrm{a}$ & $1,4 \mathrm{a}$ & $2,1 \mathrm{a}$ \\
\hline \multirow[t]{2}{*}{ Médias } & 3,3 & 2,1 & 1,6 & 1,4 & 2,1 \\
\hline & & & NPPB & & \\
\hline 20 & $16,0 \mathrm{a}$ & $4,8 \mathrm{a}$ & $3,1 \mathrm{a}$ & $3,6 \mathrm{a}$ & $6,9 \mathrm{a}$ \\
\hline 40 & $13,4 \mathrm{a}$ & $6,1 \mathrm{a}$ & $5,9 \mathrm{a}$ & $4,6 \mathrm{a}$ & $7,5 \mathrm{a}$ \\
\hline $20 / 40$ & $17,2 \mathrm{a}$ & $7,0 \mathrm{a}$ & $3,9 \mathrm{a}$ & $4,0 \mathrm{a}$ & $8,0 \mathrm{a}$ \\
\hline $20 / 60$ & $12,1 \mathrm{a}$ & $6,4 \mathrm{a}$ & $5,3 \mathrm{a}$ & $4,1 \mathrm{a}$ & $7,0 \mathrm{a}$ \\
\hline \multirow[t]{2}{*}{ Médias } & 14,6 & 6,1 & 4,5 & 4,1 & 7,3 \\
\hline & & & NPPB3G & & \\
\hline 20 & $9,1 \mathrm{a}$ & $2,1 \mathrm{a}$ & $1,0 \mathrm{a}$ & $1,3 \mathrm{a}$ & $3,4 \mathrm{a}$ \\
\hline 40 & $6,7 \mathrm{a}$ & $2,4 \mathrm{a}$ & $2,9 \mathrm{a}$ & $1,6 \mathrm{a}$ & $3,4 \mathrm{a}$ \\
\hline $20 / 40$ & $7,9 \mathrm{a}$ & $2,4 \mathrm{a}$ & $1,5 \mathrm{a}$ & $1,5 \mathrm{a}$ & $3,5 \mathrm{a}$ \\
\hline $20 / 60$ & $6,0 \mathrm{a}$ & $2,9 \mathrm{a}$ & $2,4 \mathrm{a}$ & $1,7 \mathrm{a}$ & $3,1 \mathrm{a}$ \\
\hline \multirow[t]{2}{*}{ Médias } & 7,4 & 2,5 & 2,0 & 1,5 & 3,3 \\
\hline & & & NPPB2G & & \\
\hline 20 & $6,1 \mathrm{a}$ & $2,2 \mathrm{a}$ & $1,5 \mathrm{a}$ & $1,9 \mathrm{a}$ & $2,9 \mathrm{a}$ \\
\hline 40 & $5,7 \mathrm{a}$ & $2,9 \mathrm{a}$ & $2,4 \mathrm{a}$ & $2,4 \mathrm{a}$ & $3,3 \mathrm{a}$ \\
\hline $20 / 40$ & $8,0 \mathrm{a}$ & $3,4 \mathrm{a}$ & $2,0 \mathrm{a}$ & $2,0 \mathrm{a}$ & $3,8 \mathrm{a}$ \\
\hline $20 / 60$ & $5,2 \mathrm{a}$ & $3,2 \mathrm{a}$ & $2,4 \mathrm{a}$ & $2,2 \mathrm{a}$ & $3,2 \mathrm{a}$ \\
\hline \multirow[t]{2}{*}{ Médias } & 6,2 & 2,9 & 2,1 & 2,1 & 3,3 \\
\hline & & & NPPB1G & & \\
\hline 20 & $0,7 \mathrm{a}$ & $0,5 \mathrm{a}$ & $0,4 \mathrm{a}$ & $0,4 \mathrm{a}$ & $0,5 \mathrm{a}$ \\
\hline 40 & $0,9 \mathrm{a}$ & $0,7 \mathrm{a}$ & $0,4 \mathrm{a}$ & $0,5 \mathrm{a}$ & $0,6 \mathrm{a}$ \\
\hline $20 / 40$ & $1,1 \mathrm{a}$ & $0,5 \mathrm{a}$ & $0,3 \mathrm{a}$ & $0,4 \mathrm{a}$ & $0,6 \mathrm{a}$ \\
\hline $20 / 60$ & $0,8 \mathrm{a}$ & $0,7 \mathrm{a}$ & $0,4 \mathrm{a}$ & $0,2 \mathrm{a}$ & $0,5 \mathrm{a}$ \\
\hline Médias & 0,9 & 0,6 & 0,4 & 0,4 & 0,5 \\
\hline
\end{tabular}

* Médias seguidas pela mesma letra na coluna não diferem entre si pelo teste de Tukey a 5\% de probabilidade. Fonte: Elaborado pelos Autores 
Figura 7. Valores médios do número de ramificações primárias (NRP) da cultivar BMX Potência $\mathrm{RR}^{\circledR}$ em função do aumento na população de plantas, Rio Verde - GO, safra 2012/13.

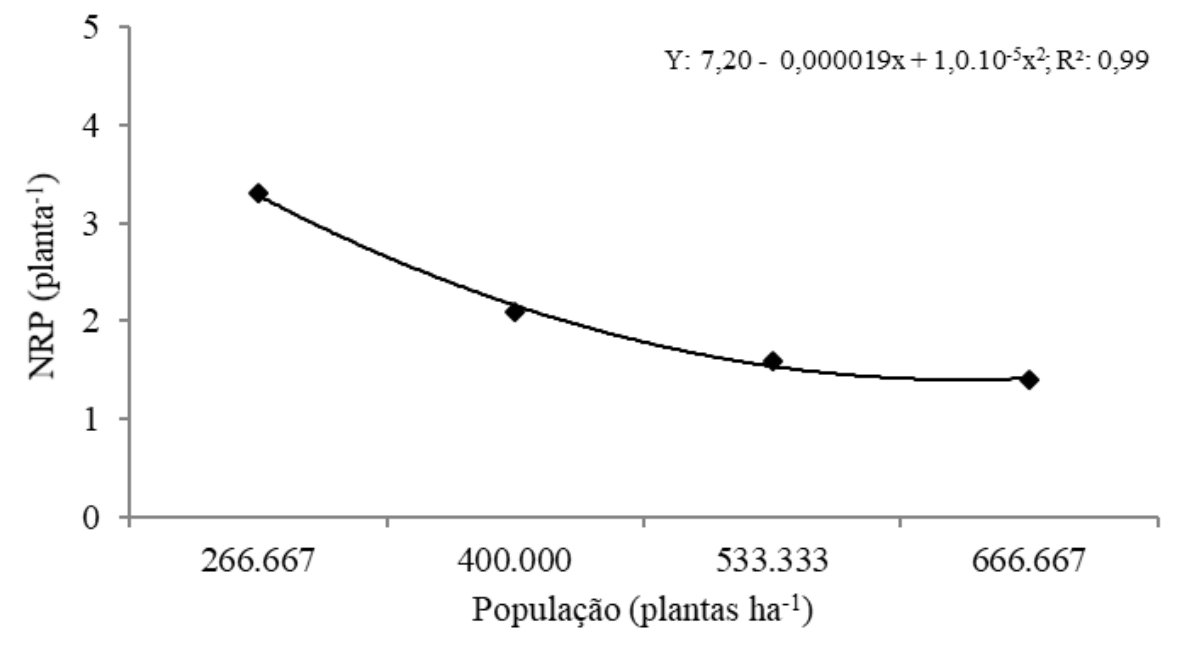

Fonte: Elaborado pelos Autores

Figura 8. Valores médios do número de vagens nas ramificações primárias (NVRP) da cultivar BMX Potência $R^{\circledR}{ }^{\circledR}$ em função do aumento na população de plantas, Rio Verde - GO, safra 2012/13.

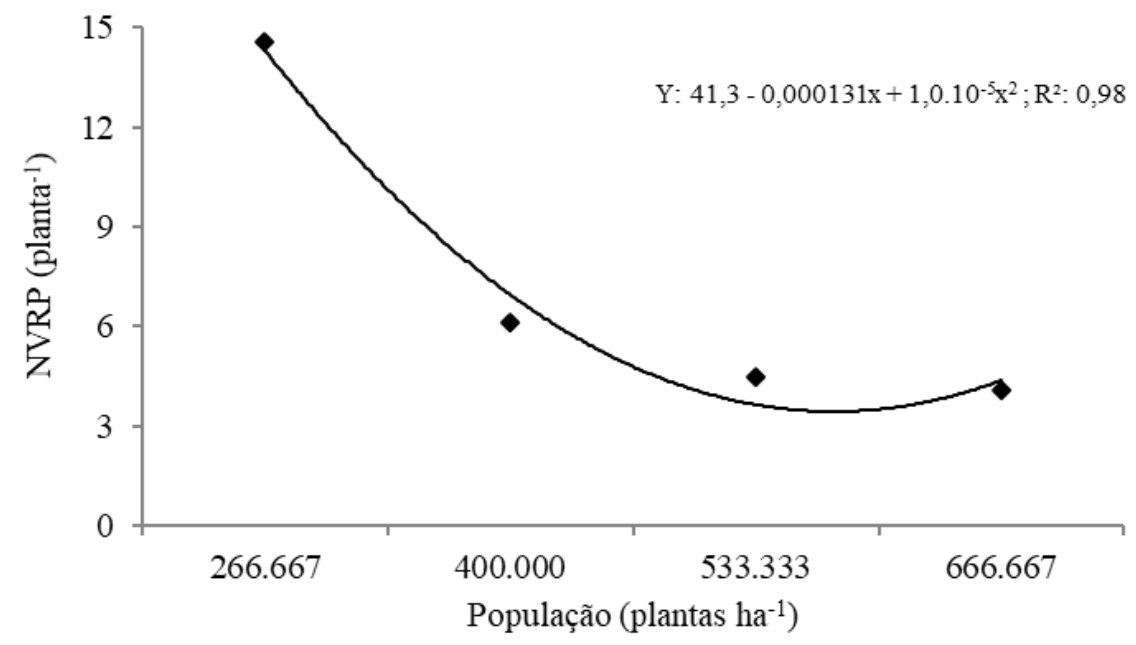

Fonte: Elaborado pelos Autores 
Figura 9. Número de vagens nas ramificações primárias (NVRP) com três, dois e um grão do cultivar BMX Potência RR $^{\circledR}$ em função do aumento na população de plantas, Rio Verde - GO, safra 2012/13.

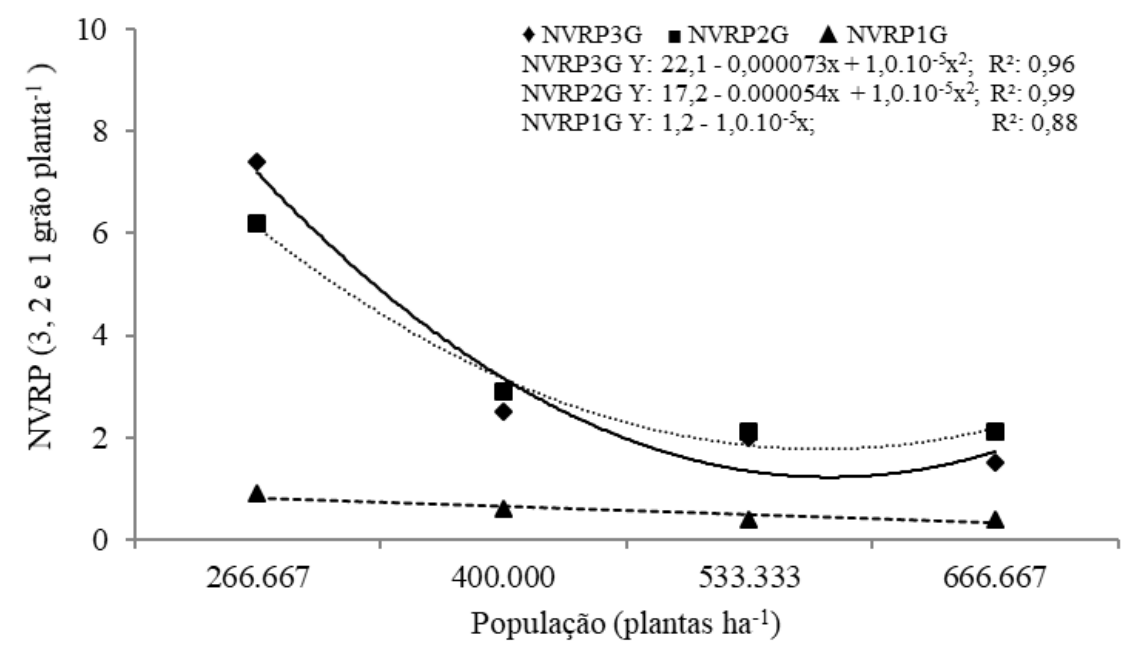

Fonte: Elaborado pelos Autores

Na avaliação de número de vagens nas ramificações primárias com três, dois e um grão observou-se decréscimos com aumento da população de plantas (Figura 9), sendo mais acentuados em relação à da haste principal. Apesar do número de vagens por planta favorecer aumentos na produtividade de grãos (LUDWIG et al., 2011), neste trabalho o menor número de vagens, e consequentemente de grãos por planta nas maiores populações do cultivar BMX Potência $\mathrm{RR}^{\circledR}$ foi compensada pelo aumento da população, gerando assim maiores produtividades de grãos.

Por outro lado, a maior distância entre as plantas na menor população minimiza a competição intraespecífica entre as plantas (MAUAD et al., 2010; LUDWIG et al., 2011). Sendo assim, o arranjo das plantas proporciona distribuição mais equidistante na área, favorecendo o aumento do número de vagens por planta (FERREIRA JÚNIOR et al., 2010; KOMATSU et al., 2010). Porém isto não ocasionou aumentos de produtividade.

Em geral, pode-se constatar que os espaçamentos entrelinhas não influenciaram a produtividade de grãos e os componentes de produção da planta, seja na haste principal ou nas ramificações primárias do cultivar BMX Potência $\mathrm{RR}^{\circledR}$. Entretanto, o aumento na população de

Nucleus, v.18, n.1, abr. 2021 
plantas em semeaduras tardias do cultivar em questão proporcionou aumento na produtividade de grãos, mesmo com redução do número vagens e de grãos por vagem por planta.

A competição intraespecífica das plantas de soja pelos fatores do ambiente, especialmente luz, determina a maior ou menor número de ramificações, ou seja, em maiores densidades de plantas, devido ao número excessivo de plantas na linha, ocorre menor disponibilidade de foto assimilados para o crescimento vegetativo das plantas na forma de ramificações (CARMO et al., 2018). Isto faz com que a planta direcione a maior parte desses foto assimilados para o crescimento do ramo principal aumentando a altura da planta, e consequentemente a altura de inserção da primeira vagem, proporcionando maior aproveitamento de área e redução nas perdas na colheita.

\section{CONCLUSÃO}

Os espaçamentos entrelinhas não influenciaram a produtividade bem como de seus componentes do cultivar BMX Potência $\mathrm{RR}^{\circledR}$.

O acréscimo de $66 \%$ na população de plantas da BMX Potência $\mathrm{RR}^{\circledR}$ proporcionou maiores produtividades e massa de mil grãos, massa seca da parte aérea, altura de plantas e de inserção da primeira vagem e redução apenas para o número de vagens na haste principal.

\section{REFERÊNCIAS}

BALBINOT JUNIOR, A.A.; PROCÓPIO, S.O.; DEBIASI, H.; FRANCHINI, J.C.; PANISON, F. Semeadura cruzada em cultivares de soja com tipo de crescimento determinado. Semina: Ciências Agrárias, v.36, n.3, p.1215-1226, 2015. http://www.alice.cnptia.embrapa.br/alice/handle/doc/1022145

BALBINOT JUNIOR, A. A. ; DEBIASI, H.; FRANCHINI, J. C.; PRIETO, J. P. C.; DE MORAES, M. T.; WERNER, F.; FERREIRA, A. S. Crescimento e distribuição de raízes de soja em diferentes densidades de plantas. Revista de Ciências Agroveterinárias, v.17, n.1, p. 12-22, 2018. https://doi.org/10.5965/223811711712018012

BALBINOT JUNIOR, A. A.; DE OLIVEIRA, M. C. N.; ZUCARELI, C.; SAMPAIO, A.; FERREIRA, F. W.; E SILVA, M. A. D. A. Analysis of phenotypic plasticity in indeterminate soybean cultivars under different row spacing. Australian Journal of Crop Science, v.12, n.4, p-648, 2018. DOI: 10.21475/ajcs.18.12.04.pne1003 
BIANCHI, M.A.; FLECK, N.G.; LAMEGO, F.P.; AGOSTINETTO, D. Papéis do arranjo de plantas e do cultivar de soja no resultado da interferência com plantas competidoras. Planta Daninha, v.28, Número Especial, p.979-991, 2010. https://doi.org/10.1590/S010083582010000500006

CARMO, E.L.; BRAZ, G.B.P.; SIMON, G.A.; SILVA, A.G.; ROCHA, A.G.C. Desempenho agronômico da soja cultivada em diferentes épocas e distribuição de plantas. Revista de Ciências Agroveterinárias, v.17, n.1, p.61-69, 2018a. https://doi.org/10.5965/223811711712018061

CARMO, E.L.; ROCHA, A.G.C.; SIMON, G.A; SILVA, A.G.; BRAZ, G.B.P. Adensamento de plantas e épocas de cultivo de soja em condições de cerrado. Colloquium Agrariae, v.14, n.2, p.01-12, 2018b. DOI: 10.5747/ca.2018. v.14.n2. a201

EMPRESA BRASILEIRA DE PESQUISA AGROPECUÁRIA. Centro Nacional de Pesquisas de Solos. Sistema brasileiro de classificação de solos. 2 ed. Rio de Janeiro - RJ. Embrapa Solos, 2006. 306p.

FERREIRA, DANIEL FURTADO. SISVAR: A computer analysis system to fixed effects split plot type designs. Revista Brasileira de Biometria, [S.1.], v. 37, n. 4, p. 529-535, dec. 2019. doi: https://doi.org/10.28951/rbb.v37i4.450.

FERREIRA, A. S.; BALBINOT JUNIOR, A. A.; WERNER, F.; ZUCARELI, C. Yield performance of soybean cultivars with indeterminate growth habits in response to plant spatial arrangement. Semina. Ciências Agrárias, v.40, n.6, p. 2905-2916, 2019.

FERREIRA, A. S.; ZUCARELI, C.; WERNER, F.; BALBINOT JUNIOR, A. A. Plant spatial arrangement affects grain production from branches and stem of soybean

cultivars. Bragantia, v.77, n.4, p-567-576, 2018. http://dx.doi.org/10.1590/1678-4499.2017285

FERREIRA JUNIOR, J.A.; ESPINDOLA, S.M.C.G.; GONÇALVES, D.A.R.; LOPES, E.W. Avaliação de genótipos de soja em diferentes épocas de plantio e densidade de semeadura no município de Uberaba - MG. FAZU em Revista, n.7, p.13-21, 2010.

GODOI, C.R.C. de; SILVEIRA NETO, A.N. da; PINHEIRO, J.B. Avaliação do desempenho de linhagens de soja, resistentes ao complexo de percevejos, cultivadas em diferentes densidades de semeadura. Bioscience Journal, v.21, n.1, p.85-93, 2005.

GUIMARÃES, F.S.; REZENDE, P.M. de; CASTRO, E.M. de; CARVALHO, E.A.; ANDRADE, M.J.B. de; CARVALHO, E.R. Cultivares de soja [Glycine max (L.) Merrill] para cultivo de verão na região de Lavras-MG. Ciência e Agrotecnologia, v.32, n.4, p.1099-1106, 2008. https://doi.org/10.1590/S1413-70542008000400010

IBRAHIM, S.E. Agronomic studies on irrigated soybeans in central Sudan: I. Effect of plant spacing on grain yield and yield componentes. International Journal of AgriScience, v.2, n.8, p.733-739, 2012.

Nucleus, v.18, n.1, abr. 2021 
KOMATSU, R.A.; GUADAGNIN, D.D.; BORGO, M.A. Efeito do espaçamento de plantas sobre o comportamento de cultivares de soja de crescimento determinado. Campo Digit@l, v.5, n.1, p.50-55, 2010.

LIMA, W.F.; PÍPOLO, A.E.; MOREIRA, J.U.V.; CARVALHO, C.G.P. de; PRETE, C.E.C.; ARIAS, C.A.A.; OLIVEIRA, M.F. de; SOUZA, G.E. de; TOLEDO, J.F.F. Interação genótipoambiente de soja convencional e transgênica resistente ao glifosato, no Estado do Paraná.

Pesquisa Agropecuária Brasileira, v.43, n.6, p.729-736, 2008. https://doi.org/10.1590/S0100204X2008000600009

LUDWIG, M.P.; DUTRA, L.M.C.; LUCCA FILHO, O.A.; ZABOT, L.; JAUER, A.; UHRY, D. Populações de plantas na cultura da soja em cultivares convencionais e Roundup Ready ${ }^{\mathrm{TM}}$. Revista Ceres, v.58, n.3, p.305-313, 2011. https://doi.org/10.1590/S0100-204X2008000600009

MADALOSSO, M.G.; DOMINGUES, L.S.; DEBORTOLI, M.P.; LENZ, G.; BALARDIN, R.S. Cultivares, espaçamento entre linhas e programas de aplicação de fungicida no controle de Phakopsora pachyrhizi Sidow em soja. Ciência Rural, v.40, n.11, p.2256-2261, 2010. https://doi.org/10.1590/S0103-84782010001100002

MAUAD, M.; SILVA, T.L.B.; ALMEIDA NETO, A.I.; ABREU, V.G. Influência da densidade de semeadura sobre características agronômicas na cultura da soja. Revista Agrarian, v.3, n.9, p.175-181, 2010.

PROCÓPIO, S.O.; BALBINOT JUNIOR, A.A.; DEBIASI, H.; FRANCHINI, J.C.; PANISON, F. Semeadura em fileira dupla e espaçamento reduzido na cultura da soja. Revista Agro@mbiente On-line, v.8, n.2, p.212-221, 2014. http://dx.doi.org/10.18227/19828470ragro.v8i2.1469

PROCÓPIO, S.O.; BALBINOT JUNIOR, A.A.; DEBIASI, H.; FRANCHINI, J.C.; PANISON, F. Plantio cruzado na cultura da soja utilizando uma cultivar de hábito de crescimento indeterminado. Revista de Ciências Agrárias Amazonian Journal of Agricultural and Environmental Sciences, v. 56, n. 4, p. 319-325, 2013.

SEDIYAMA, T. Tecnologias de produção e usos da soja. Londrina: Mecenas, 2009. 314p.

SILVA, L.S. da.; MOURA, M.C.C.L.; VALADARES, R.N.; SILVA, R.G.; SILVA, A.F.A. Seleção de variedades de soja em função da densidade de plantio, na microrregião de chapadinha, nordeste maranhense. ACSA - Agropecuária Científica no Semi-Árido, v.6, n.2, p.7-14, 2010. https://repositorio.ufma.br/jspui/handle/123456789/807

SOUZA, R.; TEIXEIRA, I.; REIS, E.; SILVA, A. Soybean morphophysiology and yield response to seeding systems and plant populations. Chilean Journal of Agricultural Research, v.76, n.1, p.3-8, 2016. http://dx.doi.org/10.4067/S0718-58392016000100001 